\title{
Right Spermatic Artery
}

National Cancer Institute

\section{Source}

National Cancer Institute. Right Spermatic Artery. NCI Thesaurus. Code C52738.

An artery arising from the abdominal aorta, below the renal artery, that supplies the right testicle. 